Muna Morris-Adams

\title{
Topic continuity in informal conversations between native and non-native speakers of English
}

\begin{abstract}
Topic management by non-native speakers (NNSs) during informal conversations has received comparatively little attention from researchers, and receives surprisingly little attention in second language learning and teaching. This article reports on one of the topic management strategies employed by international students during informal, social interactions with native-speaker peers, exploring the process of maintaining topic continuity following temporary suspensions of topics. The concept of side sequences is employed to illustrate the nature of different types of topic suspension, as well as the process of jointly negotiating a return to the topic. Extracts from the conversations show that such sequences were not exclusively occasioned by language difficulties, and that the non-native speaker participants were able to effect successful returns to the main topic of the conversations.
\end{abstract}

Keywords: informal conversations, topic management, side sequences, NS-NNS interactions

Muna Morris-Adams: School of Languages and Social Sciences, Aston University, Birmingham B4 7ET, e-mail: m.m.adams@aston.ac.uk

\section{Introduction}

A fairly common approach to research involving L2 users and non-native speakers (NNSs) is to compare their talk with that of native speakers (NSs), and on that basis to evaluate their talk as less competent (e.g. Wong 2000). In fact, judging from much of the literature (e.g. Harder 1980; Thomas 1984; Tyler 1992; Ulichny 1997; Wong 2000; Trillo 2002), it is easy to get an impression of the non-native speaker as a poor, befuddled character who is forever upsetting the native speaker because of linguistic and interactional mismanagement. This seems to apply equally whether the NNS is a learner who fails to measure up in classroom performance, or a business user of an L2 who fails to impress sufficiently to negotiate an important deal. Irrespective of the languages 
involved or the communicative contexts, the focus of much research seems to be firmly on what the NNS cannot do in a communicative sense, or can only do badly, or with difficulty (Barraja-Rohan 2003; Cheng \& Warren 1999; Cutrone 2005; Olshtain \& Cohen 1990; Wong 2000).

This article, however, takes the same position as Cook (1999: 5), who argues that 'L2 users have to be credited for what they are - L2 users. They should be judged by how successful they are as L2 users, not by their failures when compared to native speakers ...', and therefore no comparisons will be made with the conversation strategies of native speakers.

The L2 learners in this study were able to express themselves clearly and fluently during classroom discussions about a wide variety of current issues. However, they often voiced concerns about being L2 users during social interactions with native speaker peers. This apparent mismatch formed the impetus for the research which set out to investigate how problematic informal conversations actually are for non-native speakers. It therefore attempts to throw some light on what Firth (2009: 148) refers to as 'the whole reality of additional/L2 language users and learners'.

A note on terminology may be in order here. There is considerable debate (Brutt-Griffler \& Samimy 2001; Cook 1999, 2002; Davies 1991, 2003; Liu 1999; Rampton 1990) about the appropriacy of the term 'non-native speaker', with its implications of limited competence, a one-dimensional identity and negative stereotyping. Kirkpatrick (2007: 8) amply demonstrates how difficult it is to pin down what exactly constitutes a 'native or non-native speaker', and refers to the terms as both unsatisfactory and imprecise. So far attempts to establish the use of less problematic terminology (e.g. Jenkins 2009: 90) have been unsuccessful, and the terms are still widely used in the literature. They have been used in this article on the grounds that there is an absence of universally accepted alternatives, and the term 'non-native speaker' is used more positively to refer to someone who is able to communicate in more than one language, which is a not inconsiderable achievement.

As already indicated, research into intercultural communication involving native and non-native speakers has tended to lean towards what Koole \& ten Thije (2001) describe as 'the collision perspective', i.e. where the focus is mainly on the negative outcomes of communication attempts, and which, in Shea's (1994) view, tends to put the onus for misunderstanding unfairly on the NNS. NS-NNS discourse is overwhelmingly seen as problematic discourse, and much of the extensive literature on NS-NNS interaction has shown communications in a wide range of contexts to be fraught with difficulties. Cutrone (2005), for example, investigated the use of backchannels in conversations between Japanese-British dyads, and found that the British interlocutors interpreted the fre- 
quent use of backchannels by the Japanese as interruptions or signs of impatience. This had a negative effect on communication and supported the hypothesis that 'backchannel conventions, which are not shared between cultures, contribute to negative perceptions and stereotyping' (Cutrone2005:273). Wei, Hua \& Yue (2001: 135) found that business negotiations were adversely affected because '[c]ulturally-based differences in conversational styles often result in miscommunication in intercultural transactions'. In the context of service encounters Mei (2002: 95) found that different sociopragmatic choices could lead both to perceptions of impoliteness and to misunderstanding and miscommunication.

While communication problems can undoubtedly occur in intercultural interactions, this is far from an inevitable outcome, and much current research emphasises the successful resolution of such problems and demonstrates skilful use of language and interactional resources by NNSs (Gardner \& Wagner 2005; Kurhila 2006; Meierkord 2000; Pölzl \& Seidlhofer 2006; Taleghani-Nikazm \& Huth 2010). Firth \& Wagner (2007: 808) show how NNSs 'deploy, make available, share, adapt, manipulate and creatively apply communicative resources in an on-going attempt to construct meaningful and consequential social interaction'. It is from this more positive perspective that the strategies in this article will be discussed. The moments of communicative difficulty described here are seen as a normal part of spoken interaction, and are examined not as isolated incidents of lack of understanding or misunderstanding, but from the broader perspective of their effect on topic continuity in the conversations.

In informal conversation the ability to introduce, change and maintain topics is an important skill which contributes to establishing and maintaining good relationships. However, topic management is another area of discourse where NNSs seem to fare badly. For example, Bardovi-Harlig et al. (1991: 6) found that '... learners of English are often unable to end, or close, conversations appropriately'. Much of what is known about topic management by NNSs comes from the field of second language acquisition (SLA), though the focus of the research has often been on other aspects of discourse, such as content, dominance and backchannels (Chen \& Cegala 1994; Chen 1995, 2003; Hinkel 1994; Holtzer 2002; Itakura 2002; Li 1999; Long 1983; Toyoda \& Harrison 2002). Long's influential 1983 paper showed topic management to be very largely in the hands of the NSs, and he concluded that '[n]ative speakers do a lot of work to make new conversational topics salient for the non-native speaker' (p. 134). This point is echoed by Bremer et al. (1996: 55) who observe that non-native speakers are dependent on greater explicitness in transitions to a new topic, and more recently by Holtzer (2002: 236) who states that '[a] change of topic initiated by the native speaker can pose a risk for the non-native speaker'. The following 
quote is not untypical in terms of how NNS-NS conversations are still perceived:

... when participants have little shared background (be it cultural, linguistic, or personal), the conversation is likely to be peppered with interruptions for clarification of content or language form. In conversations involving non-native speakers, this becomes readily apparent. (Gass \& Varonis 1991: 122)

It is, of course, highly debatable to what extent such outcomes apply to all conversations involving NNSs, particularly as many studies are researcher-led, or classroom-based, and involve speakers at different levels of language competence. Moreover, discourse elicited in experimental or classroom research may lack features of naturalness, either because topics have been determined beforehand, because certain tasks or goals have been set, or because the conversational partners are unacquainted. In contrast, the research discussed in this article is based on participant-led discourse recorded in social situations between partners who were already acquainted.

Research into NNS discourse has tended to concentrate on various institutional contexts, such as business (Gimenez 2001; Fung 2007), medical encounters (Cameron \& Williams 1999; Frank 2000) and education (Fung \& Carter 2007; Jenkins 2004; Liebscher \& Dailey-O'Cain 2003), whereas NNS participation in informal, social interactions has been comparatively neglected. In line with other researchers (e.g. Brouwer 2003; Eerdmans \& Di Candia 2007) I would argue that, if we are to gain substantially in our understanding of both intercultural communication and second language acquisition, we need to broaden the scope of research to investigate a wider range of interactional features to discover how these can be (and often are) effectively employed in the joint construction of situated talk between native and non-native speakers.

\section{The study}

The research reported here is part of a larger study which investigated how NSs and NNSs jointly achieve understanding and coherence in talk. It focused primarily on features of topic management, such as topic initiations, changes and transitions, and also explored the impact which any communicative difficulties may have had on the topical continuity of the conversations.

'Topic' is an elusive concept, and definitions are highly dependent on the research perspective involved. For the purpose of this study 'topic' is seen, not as a purely linear, sequential process, but as a dynamic, multifaceted entity which is at the core of conversations, and the establishment and maintenance 
of which is very much a collaborative project. The investigation therefore involved looking at topic content, at the types of topics discussed and their interpersonal relevance, as well as movements from one topic to another. Rather than trying to pin down a precise definition which would encompass all these disparate elements, Abu-Akel's (2002: 1790) definition was employed for the purpose of identifying topics in the conversations: 'A single topic as an independent entity is a topic that is not linked thematically (propositionally) or linguistically to the preceding topic.' This in turn entailed a close examination of topic boundaries, and of how a variety of coherence relations - lexical, propositional and interpersonal - were implicated in topic moves.

This article focuses more narrowly on just one aspect of topic management: the reasons for topic suspensions, and their impact on topic continuity. More specifically, it focuses on whether topics were always resumed after interruptions, and if so, how the resumption was accomplished.

\subsection{Participants and data}

The NNS participants in the ten dyadic conversations were international students studying a variety of subjects at a British university. They were all in their early twenties, and came from the following countries: Germany, France, Belgium, Slovakia, Norway, Turkey and Japan. At the time of the recordings the participants had been in England for periods varying from 10 weeks to 8 months, and their levels of English varied from intermediate to advanced. With the exception of two Japanese participants, they all spoke at least one other foreign language in addition to English. The wide range of nationalities represented in this study should contribute to a richer picture of what non-native speakers can accomplish in a second, or indeed a third language.

The students themselves chose their NS conversational partners; most of them were undergraduates at the university, and variously described by the NNS participants as classmates, flatmates or friends.

The NNS participants were issued with small, portable recorders, and the conversations took place in a variety of settings and contexts during social interactions, such as sharing a meal. The researcher was not present during the conversations, and no instructions were given with regard to topics. The recordings varied in duration from 7 to 35 minutes, with a total of 3 hours of conversation transcribed, using the transcription conventions proposed by Richards (2003); these can be found in the appendix.

Collecting examples of natural, spontaneous conversation, which is essentially a very private and personal enterprise, raises considerable problems. In 
this study it is likely that some discussion may have taken place beforehand about how to conduct the recordings and the talks. It is difficult, therefore, to overcome the well-known observer's paradox which means that participants' behaviour or talk may not be as natural as when no observer or listener is present. It is conceivable that any awkwardness would be most noticeable at the start of a recording, and that is possibly why most of these recordings were started when the conversations were well under way. The recordings are as close to being naturally occurring, spontaneous conversations as one can get without resorting to covert recordings, a possibility that was excluded in this research for ethical reasons.

As the study relied on students volunteering to participate, it was not possible to control for language level, gender or nationality, and a different combination of participants may have produced different outcomes.

\subsection{Analysis}

All the conversations were listened to in full and roughly transcribed before any analysis was undertaken. The approach to analysis was therefore, in the words of Heritage (1984: 243, cited in Silverman 2005: 185), '... strongly "datadriven" - developed from phenomena which are in various ways evidenced in the data of interaction'.

The conversations were found to flow smoothly, moving easily from one topic to another. This was in large part due to the effective management of topics, with coherent changes and transitions. The analysis of topic boundaries made considerable use of insights and terminology from conversation analysis (e.g. Button \& Casey 1984; Drew \& Holt 1998; Sacks, in Jefferson 1995). Since the focus was primarily on the contributions of the non-native speakers, an additional dimension in the analysis involved attending to how these identities were at times oriented to in the talk.

In these conversations there was little evidence of differential language expertise being an issue, though the careful sequential analysis of the data revealed the existence of a number of short sequences where the topic in progress was temporarily put on hold while a linguistic or other issue was clarified. In the context of topic management in native/non-native interactions these sequences emerged as interesting phenomena which merited further scrutiny.

Sequences of talk which seem to constitute 'time out' from the main business of the talk have been identified by conversation analysts as side sequences. Jefferson (1972) described such temporary hold-ups in the progress of the talk 
and showed how they fitted into the overall conversational structure, so that there would be an ongoing sequence, a side sequence and a return to the ongoing sequence.

Svennevig (1999: 256) distinguishes between a number of different types of side sequence, and describes the overall function of side sequences as being one of aligning contextual resources to enable participants to negotiate common ground, which in turn provides the foundation for mutual understanding. He proposes two types of side sequence which '... concern the communicative process itself and thus involve a departure from the informational focus of the talk' (Svennevig 1999: 277). One of these is a monitor sequence, where the speaker stops 'to signal problems of production' (Svennevig 1999: 279). This type of sequence is therefore initiated by the current speaker, and in my data was always initiated by the NNSs, though as Svennevig's research involved NSNS interactions (in Norwegian), it is clearly the case that such monitoring of what needs to be said next and how best to say it is a problem which is not exclusive to non-native speakers.

A second type of sequence is repair sequence which is

... aimed at assuring common ground based on linguistic co-presence, that is, establishing mutual manifestness of assumptions expressed in, or implied by, prior discourse. (Svennevig 1999: 277)

In other words, a language issue needs to be resolved to ensure understanding, and in the data such sequences were always initiated by the hearer, again mostly by the NNSs.

The third type of side sequence Svennevig calls a resource scanner (1999: 286). These sequences are used 'to check or display background knowledge of matters treated in the main sequence'. In other words the topic in progress is put on hold while one of the participants checks on an aspect of factual, cultural, or interpersonal knowledge which may be consequential for the continuation of the topic. Resource scanner sequences do not, therefore, focus on linguistic problems.

A key point to be made about all the side sequences is that they retain a degree of coherence with previous talk. Svennevig (1999: 288) observes that '[t]hey establish both continuity, by referring anaphorically or cataphorically to (parts) of the main sequence, and discontinuity, by changing the focus on the topic'.

The analysis of side sequences in the data focused on the procedures which participants employed to establish understanding, looking not just at the trouble source, how this was signalled, and what the outcome is, but also at the eventual restoration of the original topic. 


\section{The findings}

The extracts presented here will exemplify the three types of side sequence, with arrows indicating where the current topic is suspended and the side sequence starts. All names are pseudonyms.

\subsection{Monitor sequences}

The NNSs frequently monitored their own speech production, by repeating or searching for words during a turn. In some cases a specific word was essential for meaning to be conveyed, while in other cases the actual word was less important for meaning; instead, the monitoring process revealed either uncertainty about a word or simply a desire to know the most appropriate word to use in the context under discussion.

A search for words might involve suggesting one or more lexical items, produced with questioning intonation. This strategy, according to Hosoda (2006: 47) '... is used when a speaker is uncertain whether for this recipient a certain recognitional form (usually a name) he/she used is appropriate to secure recognition (Sacks \& Schegloff 1979: Schegloff 1996)'. He points out that it is a strategy which is also employed by NSs. Word searches may be resolved without affecting the flow of the topic, and without intervention by the NSs, but more often than not there were direct or indirect appeals to the NS partner for help. Ten monitoring sequences leading to temporary suspension of the topic were found in the conversations, and some examples are provided below.

Most of the word searches in the conversations were fairly quickly sorted out and had minimal impact on the topics, as demonstrated in the following extract. Here Sara is describing features of her hometown in former East Germany to her English friend, Ann:

(1) Sara (NNS), Ann (NS)

528 Sara: and there's a small town Frankfurt=

529 Ann: $=$ uh=

530 Sara: =next to the Polish Oder and eh this town is having

$531 \rightarrow$ eh $<$ ship eh type eh com- company or $>(1.0)$ manufacture((r))

532 Ann: >all right yeah yeah< manufacturing yeah.

533 Sara: manufacturing very ( $\mathrm{xxx} \mathrm{xxx})$ that will create work.

534 Ann: that will create lots of jobs.

535 Sara: like thousands like thousands like thousands o' jobs.

536 Ann: u::h (1.0) which will be really beneficial for them won't it ?

537 Sara: yeah yeah because eh (..) if you compare that the stre::ets 
In line 531 Sara struggles to find the exact words she wants to use, trying out a variety in quick succession, with the final word being manufacture or manufacturer. Ann responds in line 532 with several acknowledgement tokens, as well as a reformulation of the key word to signal that she understands what Sara is trying to say. A common tactic employed by the NNSs when a word has been confirmed or provided seems to be to offer a repetition, and such repetitions work to re-connect with the topic which has been momentarily put on hold. In line 533 Sara repeats the word manufacturing and then continues to make the point that it will create work. Ann shows her understanding by a reformulation which effectively repeats the same point. The disruption has been momentary and brief, understanding has been reached, and the topic is successfully resumed. The more rapid speech in lines 531 and 532 of this side sequence may additionally indicate that that the participants orient principally to the informational content of the topic rather than to the language issue.

A different version of a word search is in operation in the next extract from the same conversation. Sara is about to tell Ann about a collection of paintings owned by the Spanish royal family:

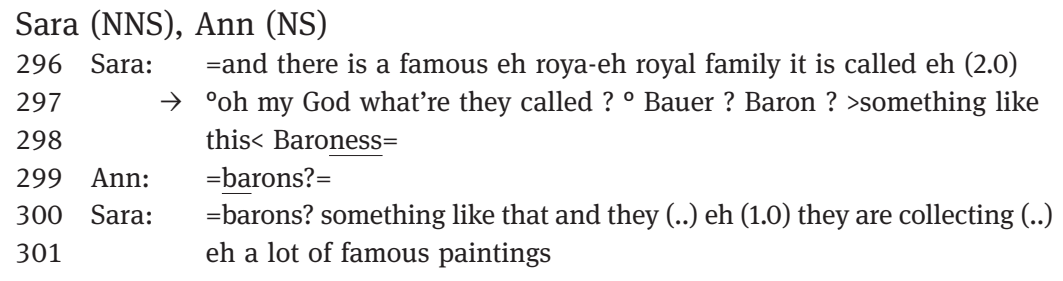

In line 296 Sara starts to talk about the Spanish royal family, but is uncertain about the exact royal title. In line 297 she abandons the main topic, i.e. what she was going to say about the royal family, and instead hesitates, and then produces an explicit word search marker what're they called ? Brouwer (2003: 537) says about such explicit word search markers that, although they may take the form of a question, they do not interactionally 'function as a question posed to the interlocutor'. They are not, in other words, requests for help with unknown vocabulary, but 'rather a technique that is used to produce a mutually recognizable reference in otherwise problematic talk'. That it is not a request for help in this case can be seen from the facts that Sara speaks this phrase in a quieter voice, as if talking more to herself than to her partner, and that she immediately after her question suggests several different titles. Ann suggests the word barons in line 299, which Sara repeats and then comments something like that, thereby acknowledging Ann's contribution. That the exact name is not crucial can be seen from the fact that she then carries on with the main point 
of her story, using and they to continue what she intended to say about the Spanish royals. She has therefore successfully retained her grip on the topic, in spite of the momentary interruption.

The next two extracts involve direct appeals to the NSs for help with language issues. In the first example the NNS stops in mid-turn to make an appeal for help with a vocabulary item. Bella, who is French, is laughingly explaining why she was not initially keen to try Max's lunch of beans on toast:

(3) Bella (NNS), Max (NS)

153 Bella: (laughing) I have prejudices because (2.0) it doesn’t look very

$154 \rightarrow$ e::h how do you say? you don't really want to eat it (1.0) $>$ How do you

155 say ? <=

156 Max: =it doesn't look very appetising.

157 Bella: yeah appetising.

158 Max: no appetising is you want to eat it

159 Bella: yeah a::h yeah. (2.0) but finally. (1.0) it’s good.

In line 154 Bella stops and asks Max to help find the right expression. She provides a competent paraphrase of what she wants to say, and then repeats her request. Max in line 156 provides not just a word, but a full sentence in explanation. Bella provides an acknowledgement token and repeats the key word to show she accepts that this was exactly the vocabulary item that she was searching for. It would complete her initial, unfinished utterance from line 153: it doesn't look very ... However, in line 158 Max steps in with a correction, which appears both unnecessary and inappropriate here, and which extends the negotiation sequence. In line 159 Bella again uses acknowledgement tokens to indicate that she has indeed understood how the word is to be used. In the same turn she returns to the topic by commenting that in spite of the way it looks, it does taste good.

In the next extract Laura, who is from Slovakia, and her English friend, Claire, are exchanging anecdotes about bee stings. On several occasions Laura seeks confirmation from her partner that she is using the right word to describe what happened, and she uses several different strategies to elicit the information:

(4) Laura (NNS), Claire (NS)

408 Laura: a father of my - one of my friends in Slovakia was .hhh (2.0) eh

$409 \rightarrow$ what's it called ? the bee sting ? so he was he has

$410 \rightarrow$ been stung ? =

411 Claire: =yeah=

412 Laura: $\rightarrow$ =stung by I think about twenty bees to the kop- eh 413 head $=$ 


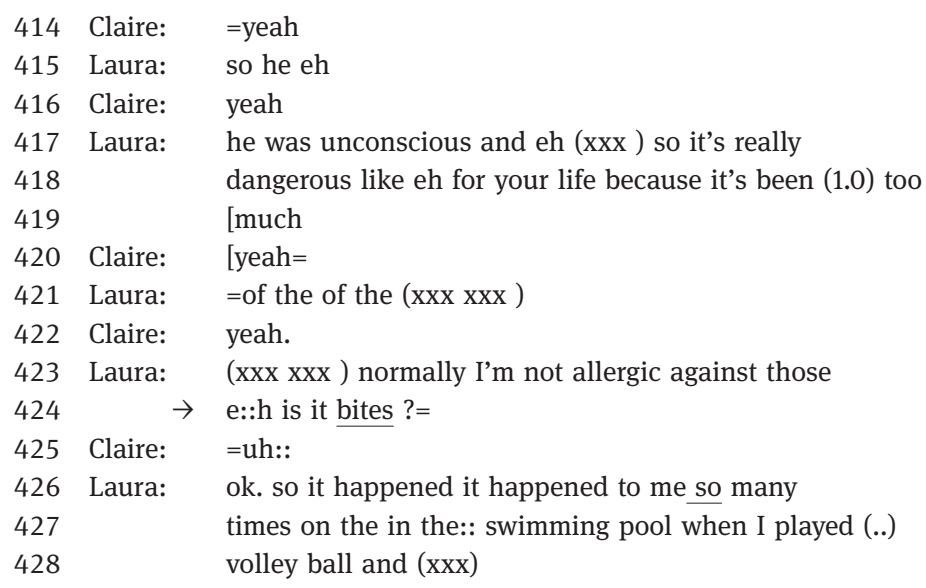

In lines 409 and 410 Laura produces both an explicit word search marker like Sara in extract (2) and a past tense form with questioning intonation to check if her usage is correct. Claire briefly confirms that it is, and Laura repeats the key word and incorporates it neatly into the continuation of her story. In line 424 she is again uncertain about a word, and this time she asks Claire directly if bites is the right word. Following Claire's confirmation, Laura uses ok to acknowledge receipt of the information, and continues to talk about experiences of being stung by wasps. In spite of several similar requests for help with vocabulary, there is evidence in this conversation of continued involvement and interest in each other's stories, and the momentary disruptions cannot, therefore, be said to have a major impact on the topic development.

These examples show how the NNSs work hard to get their meanings across without abandoning the topics in progress, and also how they successfully manage to resume or continue talking on-topic after the very brief interludes to clarify language issues. Their topic returns were invariably coherently managed, often with the help of a repetition. The repetitions functioned both to link back to the main topic and to acknowledge receipt of confirmation and information.

\subsection{Repair sequences}

Repair sequences differ from monitor sequences in that the topic suspensions are other-initiated, i.e. by the listener rather than the current speaker. However, they have in common with monitor sequences that the talk which occurs within a repair sequence is peripheral to the current topic of the conversation. The repair item or trouble source which becomes the focus of attention is, according 
to Svennevig (1999: 262), '... marked as background information in that it is not presented as relevant in its own right, but only as support for some presentation in the previous or subsequent discourse'.

The main communicative purpose of a repair sequence, then, is to resolve the linguistic difficulty so that the conversation can continue on track, i.e. with the on-going topic intact. Hence, repair sequences are part of the process of negotiating and achieving understanding in talk.

Two examples from the same conversation will serve as illustrations of repair sequences, and in the first extract it is the NS, Will, who initiates the repair. Fay, who is Belgian, is talking about her dissertation, and the fact that she is writing it in English and not in her first language, French:

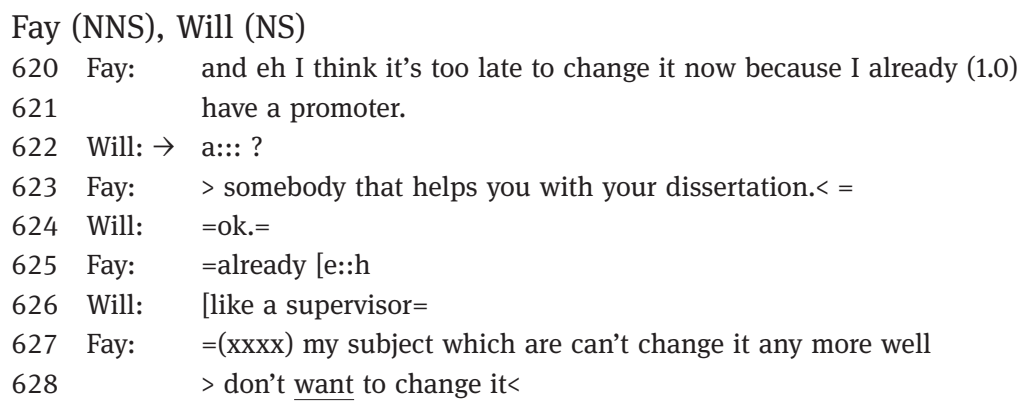

In line 621 Fay uses an inappropriate term to describe her dissertation supervisor, and Will seeks clarification by means of a long-drawn out $a:::$ ? with questioning intonation, thus prompting her to clarify the meaning. She immediately provides an explanation which Will accepts. She then picks up where she left off, with a repetition of the word already, but in overlap with her slight hesitation, Will interrupts, supplying the appropriate term for promoter, namely supervisor. There is no audible evidence that Fay acknowledges this contribution to her English vocabulary, or sees it as a repair, as she merely continues her talk on being unable to change the language of her dissertation. It may be that she already knows the correct word, or simply that it is not of great importance in this context. Mutual understanding has been achieved by a joint effort, and a return to the main topic has been effected.

In the second extract from the same conversation it is the NNS, Fay, who initiates a repair in response to an unfamiliar term used by her partner. They have been discussing the unfavourable treatment by the media of Cherie Blair, the former Prime Minister's wife: 
(6) Fay (NNS), Will (NS))

214 Will: but then (..) before him was Margaret Thatcher wasn't

215 it? and her husband Norman and he did nothing. I think it's just

216 because (..) Cherie Blair is probably so (1.0) high profile she's a QC

217 she's a barrister=

218 Fay: $\rightarrow \quad \Rightarrow$ what's that $<$ ?

219 Will: QC? eh it's just a (1.0) extra-qualified barrister.=

220 Fay: $=$ I see $=$

221 Will: sort of higher ( $\mathrm{xxxx}$ ) but as I say it's just because she's such a high-

222 profile .hhh (2.0) first lady ${ }^{\circ}$ if that's what you want to call her ${ }^{\circ}($.)

223 that they're having a go.

In line 214 Will suggests a possible reason for the unfavourable media treatment, namely that Cherie Blair's position as a barrister makes her high-profile. In line 218 Fay asks a direct question about the meaning, without specifying whether she is referring to QC or barrister. Will repeats the word QC, possibly on the understanding that this is the troublesome word, and provides an explanation. Fay accepts this with a brief I see to signal her understanding, after which Will adds a further, partly inaudible expansion of his explanation before resuming the topic with but as I say, which therefore works to link back to the original comment which he started in line 214.

Both the monitor and repair sequences illustrated here would seem to indicate that negotiations due to language issues do not inevitably have a detrimental effect on topic continuity in NS-NNS conversations.

\subsection{Resource scanner sequences}

We have seen how in monitor and repair sequences the purpose was to establish understanding of a specific word or phrase, but the concept of understanding is of course much more complex than just knowing the meaning of what is being said at a linguistic level. Shared knowledge of what is being talked about is also a pre-requisite for mutual understanding, and in intercultural encounters the existence of such shared knowledge cannot always be taken for granted. It may be necessary, therefore, for one of the participants to 'scan' or check whether the co-participant has the required content knowledge to enable talk on the topic to continue. So rather than dealing with a troublesome language issue or gap, resource scanner sequences deal with potential gaps in factual, interpersonal or cultural background knowledge.

In many of the resource scanner sequences a simple confirmation check was often sufficient to establish the existence of what Svennevig (1999: 284) 
refers to as 'the necessary expertise for continuing the main sequence in a certain way', and we can see an example of this in the extract below.

Fay and Will are discussing their preferences for various newspapers:

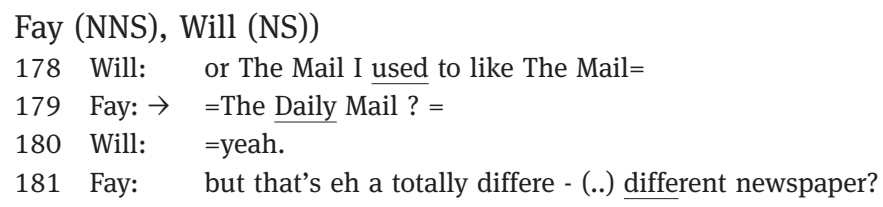

In line 179 Fay checks that she has understood correctly which newspaper Will is referring to. This is sensible insofar as the local newspaper is often referred to as The Mail. Will briefly confirms that she is right, and she then goes on to give her opinion of this paper. In other words, the main business of the talk is resumed by the NNS after this peripheral side sequence, with minimal disruption to the ongoing topic.

In the next extract Sara and Ann have been talking about the lack of attractions in Birmingham, and in line 072 Ann compares this city with London:

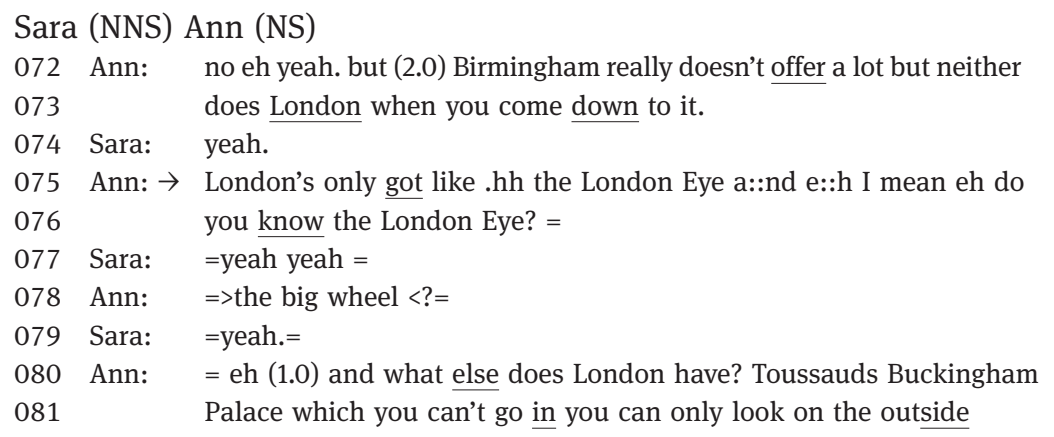

Ann's comment in line 073 about London is met with an acknowledgement token by Sara, after which Ann claims in line 075 that the London Eye is the only attraction. Before going any further she produces I mean and checks that Sara is familiar with this attraction. Fox Tree \& Schrock (2002) claim the basic meaning of I mean to be one of warning of an upcoming adjustment in the talk, and that it may also mitigate potential face threats, and these seem likely functions here. Ann shows awareness of Sara's status as a 'non-native', and a concern to ensure that common ground is established. That Sara is indeed familiar with the London Eye can be seen from her repeated yeah yeah, but Ann nonetheless gives additional confirmation by providing a brief description, which in turn receives further confirmation from Sara in line 079. Having thus estab- 
lished that they share the requisite background knowledge, Ann picks up the thread of the main business of the talk, that is, what London has to offer.

A final example of a resource scanner sequence shows how the NNS persisted in effecting a return to the topic, in spite of several brief interruptions for clarification and confirmation by her NS partner. Aya, who is Japanese, is in the process of telling Fiona an anecdote about a very hot curry cooked by an Indian friend, and that they were expected to eat it with their hands:

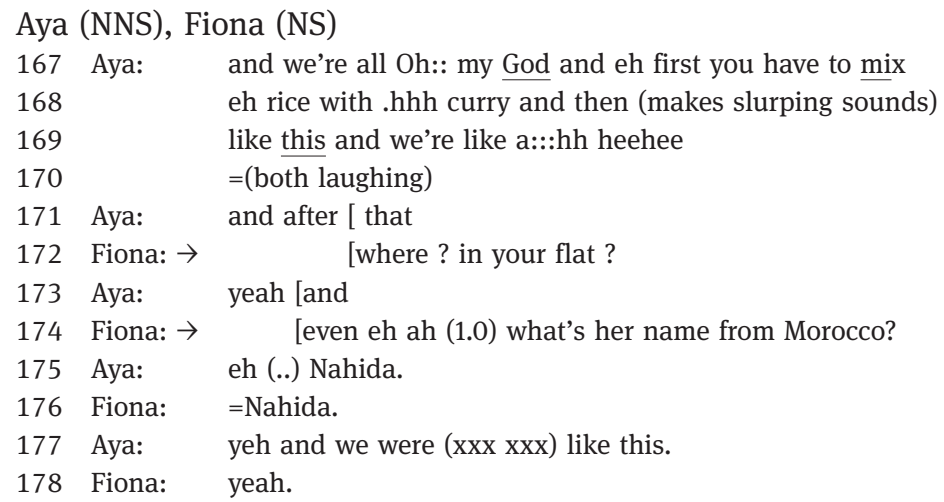

Following their laughter in line 170, Aya attempts to continue the story, but is interrupted by a request for factual information from Fiona in line 172. She provides the confirmation and again attempts to resume with and. However, at this point Fiona has another question about the name of Aya's flatmate. Aya provides the name, which Fiona then repeats for confirmation, and Aya, for the third time, produces and in line 177 to get on with the topic and her story, and this time she succeeds.

The use of the conjunction and was fairly frequent in topic returns. Turk (2004) suggests that

\footnotetext{
[a]nd may be used to mark a speaker's continuation of an unfinished unit of talk that has been interrupted either by an aside comment from the speaker or by another conversation participant. In this way, and is shown to be a text-building device and an interactional marker that organizes ideas and performs actions in conversational discourse. (Turk 2004: 234)
}

Schriffrin (1987: 147) similarly points out that 'and marks a speaker's definition of what is being said as a continuation of his/her own prior talk'. Moreover, she notes that and can impose 'a continuative effect on discourse whose structure had actually warranted otherwise', as might be the case with the side sequences discussed here. 
There were also indications that repetition of key words plus the addition of new information was one way in which a coherent topic return could be accomplished. However, on the basis of such a small data base it is not feasible to provide any generalisations about the strategies used by the NNSs. What is evident, though, is their ability to provide some sort of link with prior talk at the point of topic returns to maintain coherence.

\section{Discussion and conclusion}

The construction of mutual understanding in conversation is not dependent on language use alone, but also on the existence or establishment of personal, social or cultural background knowledge relating to the topics under discussion. The process involved in negotiating understanding at a non-linguistic level will not necessarily constitute a communicative difficulty, but it may, like language repairs, temporarily divert attention away from the current topic of a conversation. These extracts have shown that both NSs and NNSs do their utmost to ensure that the interactional goals of the conversations are achieved, and that the participants employ a range of strategies to negotiate meaning and understanding and to keep the conversations going.

The analysis of all the conversations showed that there were comparatively few side sequences; they were not, therefore, as in the quote by Gass \& Varonis (1991: 122), 'peppered with interruptions', and nor did language difficulties have a detrimental effect in these intercultural encounters. Language problems related primarily to individual lexical items, occasionally because unfamiliar terms were used by the NS partners, but most often because the NNSs needed to search for appropriate words. They monitored their own speech production, not in order to demonstrate correct language use, as in the classroom, or to clarify incomprehension on the part of their NS partners, but in order to ensure understanding in this interactional context.

The resource scanner sequences showed that intercultural differences similarly proved largely unproblematic for these conversational participants. Indeed there was evidence that such differences on occasion seemed to function as a resource for topic-making and as a focus for making interpersonal comparisons, thereby contributing to greater understanding between the parties. Resource scanner sequences showed how any uncertainties relating to different cultural backgrounds could be quickly resolved. These instances were in many cases not so very different from what could be found in a conversation between two native speakers from different parts of the UK, who are not familiar with each other's geographical or social territory. Research which takes a 'problem' 
approach to intercultural interactions, such as the studies mentioned in the introduction, would probably class such instances as evidence of 'difficulty', whereas for the participants themselves they may not present any serious obstacles to communication, nor do the sequences necessarily disrupt the flow of the conversations.

Where communicative difficulties do arise in conversations, the process of identifying and resolving them and of negotiating a return to the topic can be usefully captured by the concept of side sequences. Because the categories of monitor, repair and resource scanner sequences focus on communicative functions, they allow for a nuanced view of those instances where understanding between conversational partners needed to be negotiated. Thus the analysis showed that not all the side sequences in these NS-NNS conversations were related to linguistic difficulties, and additionally showed how different types of language issues could lead to temporary topic suspensions. Furthermore, the mere fact that communicative difficulties were dealt with in brief side sequences is evidence that they did not permanently disrupt the topics in progress. There were no instances at all in the conversations where topics were permanently abandoned because of linguistic or other difficulties.

The side sequences in the conversations represented, in the words of Kurhila (2006: 20), merely 'cracks in the progress of the conversations' which could be quickly repaired before returning to the main business of the talk. Moreover, the NNSs worked collaboratively with their NS partners to create conversations that were of mutual interest; they initiated and changed topics appropriately during the conversations, and contributed effectively to a wide range of topics. These findings therefore demonstrate considerable conversational competence on the part of the NNSs, and may go some way towards dispelling the notion that NNSs, or indeed L2 learners, are inevitably 'deficient communicators'.

Nakamura (2008: 266) suggests that '[1] ooking at informal (i.e. non-instructional) dyadic talk outside of the classroom offers us a unique and extended glimpse into how talk is co-constructed', and such investigations might additionally provide information about learning processes which may occur during social interactions. While language learning was not a focus in this study, there may be some grounds for assuming that the NNSs at times orient to learning, and that the word searches and reformulations employed in the side sequences presented here may lead to gains in vocabulary acquisition or consolidation. Further research may also reveal how or whether particular discourse skills are acquired during informal conversations, but it seems safe to conclude, as does Nakahama et al. (2001: 377), that '... conversational interaction has the potential to offer substantial learning opportunities at multiple levels of discourse'. Firth \& Wagner (2007: 812) suggest that 'much more research into the specifics 
of social interactions in L2 environments is clearly necessary' in order to gain a better understanding of the links between learning and interaction.

The aim of this article has been to present an exploratory study of what happens in informal, social conversations between native and non-native speakers, with a specific focus on one aspect of topic management. Because the data base is small, it is not possible to generalise about the results, but they nonetheless contribute to the growing number of studies which focus on the successful accomplishments of non-native speakers. Lafford (2007: 747) suggests that '[w]e need to study learners' linguistic successes as well as their failures in order to get a fuller picture of how people face communicative challenges'. The results of research from such a perspective might contribute to a more positive image of the interactional achievements demonstrated by nonnative speakers when engaged in intercultural communication.

\section{Bionote}

Muna Morris-Adams has extensive experience of teaching both foreign languages and EFL in a wide range of contexts. She holds a PhD in Applied Linguistics and is a lecturer at Aston University, Birmingham, UK, where she teaches on undergraduate and postgraduate programmes, both on-campus and by distance learning, as well as supervising $\mathrm{PhD}$ students. Her main research interests are teacher education, language teaching methodology, classroom interaction and intercultural communication.

\section{Transcription conventions}

(Adapted from Richards 2003: 173-174).

[ start of overlapping talk

$=\quad$ latched utterances

(xxx) indicates inaudible word or short phrase

(xxx $\mathrm{xxx})$ indicates longer stretch of inaudible talk

(.. ) pauses of less than one second - one dot representing 0.25 second

(2.0) timed pause (seconds)

( ) descriptions of non-verbal sounds e.g. laughter

(( )) explanation; uncertain transcription

- $\quad$ cut-off word

: $\quad$ elongated vowel

? rising intonation

. falling intonation 


$\begin{array}{ll}- & \text { emphasis } \\ . \text { hhh } & \text { inhalation } \\ ---- & \text { fragments removed from transcript } \\ \circ \circ & \text { quieter than surrounding talk } \\ <> & \text { slower than surrounding talk } \\ >< & \text { quicker than surrounding talk } \\ \text { Capitals } & \text { spoken loudly } \\ \rightarrow & \text { indicates the start of utterance under discussion }\end{array}$

\section{References}

Abu-Akel, A. 2002. The psychological and social dynamics of topic performance in family dinnertime conversation. Journal of Pragmatics 34. 1787-1806.

Atkinson, J. M. \& J. Heritage (eds.). 1984. Structures of social action. Cambridge: Cambridge University Press.

Barraja-Rohan, A. 2003. Past troubles-talk in non-native-native interviews. Journal of Pragmatics 35(4). 615-629.

Bardovi-Harlig, K., B. A. S. Hartford, R. Mahan-Taylor, M. J. Morgan \& D. W. Reynolds. 1991. Developing pragmatic awareness: closing the conversation. ELT Journal 45(1). 4-15.

Bremer, K., C. Roberts, M. Vasseur, M. Simonot \& P. Broeder. 1996. Achieving understanding: Discourse in intercultural encounters. London, Longman.

Brouwer, C. E. 2003. Word searches in NNS-NS interaction: Opportunities for language learning? The Modern Language Journal 87(iv). 534-545.

Brutt-Griffler, J. \& K. K. Samimy. 2001. Transcending the nativeness paradigm. World Englishes 20(1). 99-106.

Button, G. \& N. Casey. 1984. Generating topic: The use of topic initial elicitors. In J. M. Atkinson \& J. Heritage (eds.), Structures of social action. 167-190. Cambridge: Cambridge University Press.

Cameron, R. \& J. Williams. 1997. Sentence to ten cents: A case study of relevance and communicative success in nonnative-native speaker interactions in a medical setting. Applied Linguistics 18(4). 415-445.

Chen, L. \& D. J. Cegala. 1994. Topic management, shared knowledge, and accommodation: A study of communication adaptability. Research on Language and Social Interaction 27(4). 389-417.

Chen, L. 1995. Interaction involvement and patterns of topical talk: A comparison of intercultural and intracultural dyads. International Journal of Intercultural Relations 19(4). 463-482.

Chen, L. 2003. Conversation orientation and cognitive processes: A comparison of U.S. students in initial interaction with native- versus nonnative-speaking partners. Human Communication Research 29(2). 182-209.

Cheng, W. \& M. Warren. 1999. Inexplicitness: What is it and should we be teaching it? Applied Linguistics 20(3). 293-315.

Cook, V. 1999. Going beyond the native speaker in language teaching. TESOL Quarterly 33(2). 185-209. 
Cook, V. 2002. The goals of ELT: Reproducing native speakers or promoting multicompetence among second language users? Accessed from: http://privatewww.essex.ac.uk/-vcook/OBS30.htm

Coupland, N., H. Giles \& J. M. Wieman (eds.). 1991. 'Miscommunication' and problematic talk. Newbury Park: Sage.

Cutrone, P. 2005. A case study examining backchannels in conversations between JapaneseBritish dyads. Multilingua 24. 237-274.

Davies, A. 2003. The native speaker: Myth and reality. Clevedon: Multilingual Matters Ltd.

Drew, P. \& E. Holt. 1998. Figures of speech: Figurative expressions and the management of topic transition in conversation. Language in Society 27. 495-22.

Eerdmans, S. \& M. Di Candia. 2007. Watching paint dry: The sequentiality of idiomatic expressions in NS-NS and NS-NNS talk-in-interaction. Discourse Studies 9(5). 579-595.

Firth, A. 2009. Doing 'not' being a foreign language learner: English as a 'lingua franca' in the workplace and (some) implications for SLA. IRAL 47(1). 127-156.

Firth, A. \& J. Wagner. 2007. Second/foreign language learning as a social accomplishment: Elaborations on a reconceptualized SLA. The Modern Language Journal 91 (Focus Issue). 800-819.

Fox Tree, J. E. \& Josef C. Schrock. 2002. Basic meanings of you know and I mean. Journal of Pragmatics 34. 727-747.

Frank, R. A. 2000. Medical communication: Non-native English speaking patients and native English speaking professionals. English for Specific Purposes 19. 31-62.

Fung, L. 2007. The communicative role of self-repetition in a specialised corpus of business discourse. Language Awareness 16(3). 224-238.

Fung, L. \& R. Carter. 2007. Discourse markers and spoken English: Native and learner use in pedagogic settings. Applied Linguistics 28(3). 410-439.

Gardner, R. \& J. Wagner (eds.). 2005. Second language conversations. London, Continuum.

Gass, S. \& E. M. Varonis. 1991. Miscommunication in nonnative speaker discourse. In N. Coupland, H. Giles \& J. M. Wieman (eds.), 'Miscommunication' and problematic talk, 121-145. Newbury Park, Sage.

Gimenez, J. C. 2001. Ethnographic observations in cross-cultural business negotiations between non-native speakers of English: An exploratory study. English for Specific Purposes 20(2). 169-193.

Harder, P. 1980. Discourse as self-expression - on the reduced personality of the secondlanguage learner. Applied Linguistics 1(3). 262-270.

Hinkel, E. 1994. Topic appropriateness in cross-cultural social conversations. Pragmatics and Language Learning, Monograph Series 5. 164-179.

Holtzer, G. 2002. Learning culture by communicating: Native-non-native speaker telephone interactions. Language, Culture and Curriculum 15(3). 235-242.

Hosoda, Y. 2006. Repair and relevance of differential language expertise in second language conversations. Applied Linguistics $27(1) .25-50$.

Itakura, H. 2002. Gender and pragmatic transfer in topic development. Language, Culture and Curriculum 15(2). 161-183.

Jefferson, G. 1972. Side sequences. In D. Sudnow (ed.), Studies in social interaction, 294233. New York: The Free Press.

Jefferson, G. (ed.). 1995. Lectures on conversation. Oxford: Blackwell.

Jenkins, S. 2004. Cultural and linguistic miscues: A case study of international teaching assistant and academic faculty miscommunication. International Journal of Intercultural Relations 24. 477-501. 
Jenkins, J. 2009. World Englishes. London: Routledge.

Kirkpatrick, A. 2007. World Englishes. Cambridge: Cambridge University Press.

Koole, T. \& J. D. ten Thije. 2001. The reconstruction of intercultural discourse: Methodological considerations. Journal of Pragmatics 33. 571-587.

Kurhila, S. 2006. Second language interaction. Amsterdam: John Benjamins.

Lafford, B. A. 2007. Second language acquisition reconceptualized? The impact of Firth and Wagner (1997). The Modern Language Journal 91(5). 735-756.

Li, Han Z. 1999. Communicating information in conversation: A cross-cultural comparison. International Journal of Intercultural Relations 23(3). 387-409.

Liebscher, G. \& J. Dailey-0'Cain. 2003. Conversational repair as a role-defining mechanism in classroom interaction. The Modern Language Journal 87(iii). 375-390.

Liu J. 1999. Nonnative-English-speaking professionals in TESOL. TESOL Quarterly 33(1). 85102.

Long, M. H. 1983. Native speaker/non-native speaker conversation and the negotiation of comprehensible input. Applied Linguistics 4(2). 126-141.

Mei, L. S. 2002. Contextualizing intercultural communication and sociopragmatic choices. Multilingua 21. 79-99.

Meierkord, C. 2000. Interpreting successful lingua franca interaction. Linguistik online 5, 1/00. Accessed from: http://www.linguistik-online.de

Nakahama, Y., A. Tyler \& L. van Lier. 2001. Negotiation of meaning in conversational and information gap activities: A comparative discourse analysis. TESOL Quarterly 35(3). 377-405.

Nakamura, I. 2008. Understanding how teacher and student talk with each other: An exploration of how 'repair' displays co-management of talk-in-interaction. Language Teaching Research 12. 265-283.

Olshtain, E. \& A. Cohen. 1990. The learning of complex speech act behaviour. TESL Canada Journal/ Revue TESL du Canada 7(2). 45-65.

Pölzl, U. \& B. Seidlhofer. 2006. In and on their own terms: the 'habitat factor' in English as a lingua franca interactions. International Journal of the Sociology of Language 177. 151-176.

Rampton, M. B. H. 1990. Displacing the 'native speaker': Expertise, affiliation and inheritance. ELT Journal 44(2). 97-106.

Richards, K. 2003. Qualitative inquiry in TESOL. Basingstoke: Palgrave Macmillan.

Schegloff, E. A., G. Jefferson \& H. Sacks. 1977. The preference for self-correction in the organization of repair in conversation. Language 53. 361-381.

Schiffrin, D. 1987. Discourse markers. Cambridge: Cambridge University Press.

Shea, D. P. 1994. Perspective and production: Structuring conversational participation across cultural borders. Pragmatics 4(3). 357-389.

Silverman, D. 2000. Doing qualitative research. London: Sage

Sudnow, D. (ed.). 1972. Studies in Social Interaction. New York, The Free Press.

Svennevig, J. 1999. Getting acquainted in conversation. Amsterdam: John Benjamins.

Taleghani-Nikazm, C. \& T. Huth. 2010. L2 requests: Preference structure in talk-in-interaction. Multilingua 29. 185-202.

Thomas, J. 1984. Cross-cultural discourse as 'unequal encounter': Towards a pragmatic analysis. Applied Linguistics 5(3). 226-235.

Trillo, J. R. 2002. The pragmatic fossilization of discourse markers in non-native speakers of English. Journal of Pragmatics 34. 769-784. 
Tyler, A. 1992. Discourse structure and the perception of incoherence in international teaching assistants' spoken discourse. TESOL Quarterly 26(4). 713-729.

Toyoda, E. \& R. Harrison. 2002. Categorization of text chat communication between learners and native speakers of Japanese. Language Learning and Technology 6(1). 82-99.

Turk, M. J. 2004. Using and in conversational interaction. Research on Language and Social Interaction 37(2). 219-250.

Ulichny, P. 1997. The mismanagement of misunderstandings in cross-cultural interactions. Journal of Pragmatics 27. 233-246.

Wei, L., Z. Hua \& L. Yue. 2001. Conversational management in Chinese-English business talk. Language and Intercultural Communication 1(2). 135-150.

Wong, J. 2000. Repetition in conversation: A look at 'first and second sayings'. Research on Language and Social Interaction 33(4). 407-424. 